\title{
Laser pointers revisited: a survey of 14 patients attending casualty at the Bristol Eye Hospital
}

\author{
C S Sethi, R H B Grey, C Dean Hart
}

\begin{abstract}
Aims-The largest clinical series of laser pointer exposures to date is described, to document any long term visual sequelae and assess objectively the visual threat from transient ocular exposure.

Methods-14 cases were collected prospectively and triaged by ophthalmic nurses before referral to an ophthalmologist for a complete ophthalmic examination. Regardless of the need for clinical follow up, all patients were contacted by telephone at a mean interval of 10.5 months following exposure to inquire about new or persisting symptoms.

Results-11/14 cases presented within 24 hours of exposure and 5/14 incidents were reported to the police. Reduced acuity in the affected eye compared with the contralateral were documented in 5/14 cases. The commonest physical sign was a punctate epitheliopathy, seen in 5/14 cases, and the commonest symptom was ocular discomfort, reported by $11 / 14$ patients. There were no consistent retinal findings. Follow up by telephone survey revealed that two patients were wearing new glasses, but had not been refracted before the exposure; one had intermittent ocular discomfort; the remaining 11 were asymptomatic.

Conclusions-This study is reassuring to the ophthalmology community and the general public in failing to demonstrate consistent, long term damaging effects of transient ocular exposure to laser pointer beams.
\end{abstract}

(Br f Ophthalmol 1999;83:1164-1167)

In recent years we have seen considerable media interest in the potential for laser pointers to cause significant ocular injury. There has also been much discussion among ophthalmologists about the correct classification of these devices and the theoretical power required to produce a retinal lesion. Most clinical reports have been anecdotal and reassuring but have lacked long term follow up. We describe the largest clinical series to date, collected prospectively at the Bristol Eye Hospital, and have conducted a telephone survey of all subjects with a mean follow up time of 10.5 months, to document any significant social or visual sequelae that may be related to the initial exposure.

Mr C S Sethi, Vitreo-Retinal Surgical Unit, Moorfields Eye Hospital, City Road, London EC1V 2PD.

Accepted for publication 12 July 1999
All 14 cases were collected prospectively at the Bristol Eye Hospital casualty department, which they attended either as self referrals, or following initial consultation at an accident and emergency department in the region. Triage nurses initially assessed all patients, with a comment on mode of injury, time to presentation, symptoms, and bilateral visual acuity. They were then referred to an ophthalmologist for a complete ophthalmic examination, including dilated funduscopy. Patients attending casualty before $8 \mathrm{pm}$ were examined on the same day; those attending after $8 \mathrm{pm}$ were triaged and examined fully the following morning. The clinical history recorded specifically whether the patient was in charge of a moving vehicle at the time of exposure, whether the incident had occurred in the work place, which we took to include classroom or lecture theatre, and whether the police had been informed.

Subsequent treatment and follow up were left to the discretion of the examining ophthalmologist, as it was felt that routine follow up of patients with trivial symptoms and no clinical signs could not be justified in a busy casualty department. However, regardless of clinical follow up, all patients were contacted by telephone at a mean interval of 10.5 months following exposure (range 5-12 months). The telephone consultation inquired specifically about any new or persisting visual symptoms or ocular discomfort and the outcome of any legal proceedings.

\section{Results}

Clinical data for the 14 cases are summarised in Tables 1 and 2. Thirteen cases presented over an 11 week period between October 1997 and January 1998, coinciding with interest and speculation in the media about laser pointers. ${ }^{1}$ Patient 14, a teacher, presented 4 months later, having sustained a brief exposure from a laser pointer wielded by a pupil in her classroom. Eleven of 14 cases $(78.6 \%)$ presented within 24 hours of exposure. The sex ratio was equal and the age ranged from 9 to 68 years with a mean of 34 years. The left eye alone was affected in $9 / 14$ cases $(64.3 \%)$, the right eye alone in $3 / 14$ cases $(21.2 \%)$, both eyes were affected in $2 / 14$ cases $(14.3 \%)$. The exposure was reported to have occurred in the workplace in $9 / 14$ cases $(64.3 \%)$; while driving in $4 / 14$ cases $(28.6 \%)$, and $5 / 14$ incidents $(35.7 \%)$ were reported to the police. One incident was self inflicted accidentally. In 4/14 cases $(28.6 \%)$, the "assailant" was known to the patient and these incidents have been referred to as "pranks" in Table 1 ; in $9 / 14$ cases $(64.3 \%)$, the assailant was unknown and the incident is referred to as an assault. In all cases, including the self inflicted exposure, the person aiming the laser pointer was male. 
Table 1 Details of presentation

\begin{tabular}{|c|c|c|c|c|c|c|c|c|c|}
\hline Patient & Age & Sex & Eye & Method of injury/occupation & $\begin{array}{l}\text { Time to } \\
\text { present }\end{array}$ & $\begin{array}{l}\text { Police } \\
\text { informed? }\end{array}$ & Initial signs & Initial symptoms & $\begin{array}{l}\text { Reduced visual } \\
\text { acuity? }\end{array}$ \\
\hline 1 & 26 & M & Left & Assault at work (security officer) & $<24$ hours & Yes & $\begin{array}{l}\text { Punctate } \\
\text { epitheliopathy }\end{array}$ & $\begin{array}{l}\text { Headache, discomfort, blurred } \\
\text { vision }\end{array}$ & No \\
\hline 2 & 28 & M & Left & Assault at work (bus driver) & $<3$ hours & Yes & $\begin{array}{l}\text { Punctate } \\
\text { epitheliopathy }\end{array}$ & Glare & No \\
\hline 3 & 37 & $\mathrm{~F}$ & Right & Assault while driving (civil servant) & $<24$ hours & No & Nil & Foreign body sensation & No \\
\hline 4 & 30 & M & Right & Assault at work (parking attendant) & $<24$ hours & No & Nil & Ocular discomfort & No \\
\hline 5 & 48 & $\mathrm{~F}$ & Left & Assault at work (bus driver) & $<3$ hours & No & Nil & Nil & No \\
\hline 6 & 68 & $\mathrm{~F}$ & Left & Assault at work (receptionist) & 30 days & No & $\begin{array}{l}\text { Abnormal } \\
\text { foveal reflex }\end{array}$ & Headache and blurred vision & $\begin{array}{l}\text { Yes }(6 / 6-3 ; 6 / 6 \\
\text { fellow) }\end{array}$ \\
\hline 7 & 40 & M & Right & Prank at work (internet technician) & 29 days & No & $\begin{array}{l}\text { Perifoveal } \\
\text { drusen }\end{array}$ & $\begin{array}{l}\text { Photophobia, discomfort, blurred } \\
\text { vision }\end{array}$ & $\begin{array}{l}\text { Yes }(6 / 9+4 ; 6 / 4 \\
\text { fellow) }\end{array}$ \\
\hline 8 & 41 & M & Left & $\begin{array}{l}\text { Assault while driving (insurance } \\
\text { broker) }\end{array}$ & $<24$ hours & Yes & Nil & Discomfort, blurred vision & $\begin{array}{l}\text { Yes }(6 / 9 ; 6 / 4 \\
\text { fellow) }\end{array}$ \\
\hline 9 & 9 & $\mathrm{~F}$ & Left & Prank at school (student) & $<24$ hours & Yes & $\begin{array}{l}\text { Punctate } \\
\text { epitheliopathy }\end{array}$ & Discomfort, blurred vision & $\begin{array}{l}\text { Yes }(6 / 12 ; 6 / 4 \\
\text { fellow) }\end{array}$ \\
\hline 10 & 30 & $\mathrm{~F}$ & Both & Assault in town (unemployed) & $<3$ hours & No & Nil & Discomfort, blurred vision & No \\
\hline 11 & 20 & $\mathrm{~F}$ & Both & Accident in lecture hall (student) & 14 days & No & Nil & Discomfort, glare & No \\
\hline 12 & 28 & M & Left & Assault in town (unemployed) & $<3$ hours & Yes & $\begin{array}{l}\text { Punctate } \\
\text { epitheliopathy }\end{array}$ & Ocular discomfort & No \\
\hline 13 & 31 & M & Left & Accident, self inflicted (unemployed) & $<12$ hours & No & Nil & Ocu & No \\
\hline 14 & 36 & $\mathrm{~F}$ & Left & Prank at work (teacher) & $<3$ hours & No & $\begin{array}{l}\text { Punctate } \\
\text { epitheliopathy }\end{array}$ & Discomfort, blurred vision & $\begin{array}{l}\text { Yes }(6 / 12 ; 6 / 5 \\
\text { fellow) }\end{array}$ \\
\hline
\end{tabular}

Reduced visual acuity in the affected eye compared with the fellow was documented in $5 / 14$ cases $(35.7 \%)$, though one of these (patient 14) was known to have reduced acuity following previous episodes of optic neuritis. The commonest physical sign was a punctate epitheliopathy, which was seen in $5 / 14$ cases $(35.7 \%)$. Patients had been asked about "significant" eye rubbing, defined as intermittent rubbing for more than half an hour after exposure, by the casualty officer at presentation. While $5 / 5$ cases with corneal signs admitted to eye rubbing, this was only documented in 3/9 cases lacking corneal findings (patients 6,7 , and 11). Despite the small numbers, this suggests a significant association between eye rubbing and abnormal corneal findings (Fisher's exact score 0.03). Patient 6 was noted as having an "abnormal foveal reflex" in the affected eye and patient 7 had perifoveal drusen-like deposits on funduscopy. The commonest symptom was ocular discomfort, with or without a foreign body sensation, which was described by $11 / 14$ patients $(78.6 \%)$; "blurred vision" or "dazzle" was described by $9 / 14$ patients $(64.3 \%)$ and $2 / 14(14.3 \%)$ described headaches. Only one patient was asymptomatic. None of our patients described a persisting afterimage or scotoma and no visual field defects could be demonstrated on confrontation.
Treatment with an ocular lubricant or antibiotic was considered appropriate at the time of consultation in $3 / 14$ cases. All of these had evidence of a punctate corneal epitheliopathy on presentation. A 2 week follow up assessment was arranged for $5 / 14$ patients $(35.7 \%)$. Of these one did not attend for review; patients 1 and 10 had normal physical examinations and visual acuity; patient 7 still described reduced acuity, measured at 6/9+4 on a Snellen chart, compared with $6 / 4$ in the fellow eye; patient 9 described fluctuating vision, with a Snellen acuity of 6/12 compared with $6 / 4$ in the fellow eye. The two patients with persisting visual symptoms were offered fluorescein angiography, which was normal for patient 7 and declined by the parents of patient 9.

All patients were subsequently contacted by telephone after a mean interval of 10.5 months (range 5-12 months). They were asked specifically about visual symptoms, ocular discomfort, and the outcome of any legal proceedings. Two patients (7 and 8) said that their vision had never returned to normal following laser exposure and were wearing new refractive corrections, having consulted a high street optician. Patient 14 was the only one to describe persisting symptoms of intermittent ocular discomfort.

Table 2 Treatment and follow up

\begin{tabular}{llll}
\hline Patient & Treatment at presentation & Symptoms at 2 weeks & Results of telephone survey/comments \\
\hline 1 & Viscotears four times daily & Persisting glare & At 11 months-no relevent symptoms \\
& for 1 week & No follow up & At 11 months-no relevent symptoms \\
2 & Nil & No follow up & At 11 months-no relevent symptoms \\
3 & Nil & No follow up & At 11 months-no relevent symptoms \\
4 & Nil & No follow up & At 11 months-no relevent symptoms \\
5 & Nil & Did not attend for review & At 11 months-no relevent symptoms \\
6 & Nil & Vision still blurred $(6 / 9+4)$ & At 11 months-symptoms unchanged; new glasses \\
7 & Nil & No follow up & At 11 months-visual acuity unchanged; new glasses \\
8 & Nil & Vision fluctuating (6/12) & At 11 months-no relevent symptoms \\
9 & Nil & Asymptomatic & At 12 months-no relevent symptoms \\
10 & Nil & No follow up & At 10 months-no relevent symptoms \\
11 & Nil & No follow up & At 12 months-no symptoms; unsuccessful prosecution \\
12 & Chloramphenical four & & \\
& times daily $5 / 7$ & No follow up & At 9 months-no relevent symptoms \\
13 & Nil & No follow up & At 5 months-continuing discomfort; NB old optic neuritis \\
14 & Chloramphenical four & & \\
\hline
\end{tabular}




\section{Discussion}

We have described the largest clinical series of laser pointer exposures in the current literature. Our subjects suggest that the "victim" is usually of working age and the exposure commonly occurs at the place of work. The preponderance of left eye involvement is likely to be a chance finding and the assailant was male in all cases. The incidence of punctate epithelial damage (5/14 cases) is interesting, but we would agree with Mensah et al, who described six cases in April, 1998, that this is most likely to have occurred from eye rubbing, as the cornea is transparent to diode wavelengths. ${ }^{2}$ Interestingly, the three patients in our survey who admitted to eye rubbing but lacked corneal signs all attended casualty after 24 hours and we can only speculate that these signs may have been present if they had been examined earlier.

Despite the documentation of discomfort or visual disturbance in 13/14 cases at presentation, the true motivation for seeking medical care warrants closer attention. This has been clarified by our telephone survey, undertaken after patients had had time to reflect upon their experience and conduct. Our analysis suggests that there are four main groups who seek medical advice after transient exposure to a laser pointer beam:

(1) those whose physical symptoms are their main cause for concern

(2) those who are anxious about lasting harm-the "worried well"

(3) those who see themselves primarily as victims of assault

(4) frank malingerers.

In all cases of police involvement (5/14), this occurred before medical consultation. All subsequently attended casualty within 24 hours and had been encouraged by their case officer to do so. They were universally asymptomatic at the time of our telephone survey and patient 12 had attempted, unsuccessfully, to prosecute his assailant for assault. Of the remaining nine patients, eight described physical symptoms at presentation, and appear to represent the first group. However, when asked in the telephone survey to indicate their main reason for attending casualty, these patients reclassified themselves as the "worried well", anxious to exclude ocular injury, with the exception of patient 7 , who is discussed below. Only patient 5 admitted a lack of symptoms and that reassurance was her only reason for attendance.

Of the five patients for whom follow up had been arranged, only two had visual symptoms at 2 weeks. One of these (patient 7) had attended for medical review 29 days after exposure and described no change in symptoms when interviewed by telephone 11 months after exposure, though he has independently requested a medicolegal report for a compensation claim from the first two authors of this paper. We believe that his perifoveal drusen deposits and uncorrected refractive error account for the reduced acuity in the affected eye, but were incidental findings, unrelated to the laser exposure. His delay in seeking medical advice and continuing legal involvement raises the possibility of malingering in this case. The other (patient 9) was completely asymptomatic when interviewed at 11 months after exposure. Two patients had started to wear glasses when the telephone survey was conducted, but neither had been refracted before exposure, so we assume that the uncorrected refractive error was present at the time of injury and discovered incidentally. Patient 14 was the only subject to describe persisting ocular discomfort in the telephone survey (follow up at 5 months). While she did have punctate epithelial changes at the time of exposure, this eye had also suffered several previous attacks of optic neuritis and was described as feeling occasionally being uncomfortable.

The availability of low cost laser pointing devices to the general public has given them a status more akin to toys than the presentation aid beloved of serious minded academics. We have seen advertisements describing potential uses from "playing with pets-cats and dogs love to chase the red dot!" to "having fun in night clubs they're great for getting someone's attention across the room!". Most are sold as key chains with detachable heads producing various patterns of light and they may be bought inexpensively on market stalls or via the internet. We recommend the laser safety page on the LaserBullet website (www.laserbullet.com/) to those who are interested, as one of the few examples of responsible advertising. Concern about these devices is not a new phenomenon among laser safety experts ${ }^{3}$ and stems from the fact that, where government standards are not being met regarding appropriate warnings, today's typical user cannot be expected to have complete familiarity with the precautions necessary for safe use of the product. Most products from the USA emit approximately $5 \mathrm{~mW}$ of power and are classified by the American National Standards Institute as class 3A, namely, "lasers that normally would not cause injury to the eye if viewed momentarily". "The power of a narrow beam device should not exceed $1 \mathrm{~mW}$ for a class $3 \mathrm{~A}$ classification in Europe, where the International Electrotechnical Committee reclassifies such American devices as class 3B-namely, "lasers that present an eye and skin hazard if viewed directly". This puts them in a class with a maximum power output of $500 \mathrm{~mW}$, and regarded as unsuitable for use by untrained personnel. Though the legal classifications appear contradictory, safety standards are consistent in requiring that direct eye exposure be avoided. While a normal aversion response would limit accidental exposure to less than 0.25 seconds, ${ }^{5}$ there is a theoretical risk of retinal damage on exposure to a collimated class $3 \mathrm{~A} / \mathrm{B}$ laser for several seconds. ${ }^{6}$

In an evaluation of laser pointers supplied by Scottish trading standards authorities, McGhee and co-workers classified seven out of nine devices as class $3 \mathrm{~B}$, by European standards. ${ }^{7}$ The one device recovered in our survey demonstrated a power of $3.2 \mathrm{~mW}$ through a $7 \mathrm{~mm}$ aperture (United Detector Technology photometer) and would also be 
classified as class 3B. This was a key chain pointer with no laser classification or warning on the casing and had been purchased by patient 7's work colleague from a market stall. We believe this to be typical of the devices involved in this survey, as five other patients (4, $6,9,13$, and 14), when later questioned, had been assaulted at close enough range to state that the laser involved was "a cheap one, on a key ring", or words to that effect.

We feel that our study is reassuring to the ophthalmology community and the general public in failing to demonstrate consistent, long term damaging effects of transient ocular exposure to laser pointers. We have been unable to document any ocular lesions caused by the laser exposures in this study. Most patients are sufficiently distressed to attend a casualty department within 24 hours of exposure, irrespective of symptoms, but the majority can be reassured at their first assessment, with no need for treatment or follow up. ${ }^{8}$ We recommend dilated funduscopy as part of the initial assessment, to facilitate accurate examination and documentation of the macula and to exclude underlying causes for visual loss in those cases presenting with a reduced Snellen acuity, compared with the fellow eye. There may be a small population of protanopes who have a decreased visual sensitivity at diode wavelengths near $670 \mathrm{~nm}$ and are more prone to exceeding the maximum permissible exposure $^{9}$ owing to delayed aversion. We are undertaking a follow up study to investigate this possibility, by measuring the colour contrast sensitivity of our subjects with persisting visual symptoms.

We would like to thank the triage nurses of the Bristol Eye Hospital for helping to assess patients at presentation and the casualty staff of Frenchay and Southmead hospitals for their help in identifying these cases. We also thank LaserBullet, USA, for identifying these cases. We also thank LaserBullet, USA, for
permission to quote their advertising and safety literature. This permission to quote their advertising and safety literature. This
study was not funded externally and the authors have no commercial interest.

1 Bennetto J. Youth in trouble: laser pen dangers highlighted as injuries increase. The Independent 1997;October 25:16

2 Mensah E, Vafidis G, Marshall J. Laser pointers: the facts, media hype, and hysteria (letter). Lancet 1998;351:1291.

3 Sliney DH, Dennis JE. Safety concerns about laser pointers. F. Laser Appl 1994;6:159-64.

4 American National Standards Institute. American National Standard for the safe use of Lasers, ANSI Z136.1. New York: National Standards Institute, 1993

5 Mainster MA, Timberlake GT, Warren KA, et al. Pointers on laser pointers. Ophthalmology 1997;104:1213-14.

6 Ham WT Jr, Geeraets WJ, Mueller HA, et al. Retinal burn thresholds for the helium-neon laser in the rhesus monkey. thresholds for the helium-neon lase

7 Acchop CNJ, Craig JP, Moseley H, et al. Laser keychains; McGhee CNJ, Craig JP, Moseley H, et al. Laser keychain
potential for serious eye injury. Eyenews 1997/8;4:17-19.

8 Matential for serious eye injury. Eyenews $1997 / 8 ; 4: 17-19$. Marshall J. The safety of laser point
Brf Ophthalmol 1998;82:1335-8.

9 Eagle RC Jr. Laser pointers and color blindness (letter). Ophthalmology 1998;105:760. 